\title{
LA CELESTINA EN EL FRANQUISMO: EN TORNO A UNA FRUSTRADA PELÍCULA DE JOSÉ LUIS SÁENZ DE HEREDIA*
}

\author{
CELESTINA DURING THE FRANCO REGIME: NOTES ON A \\ FRUSTRATED FILM PROJECT BY JOSÉ LUIS SÁENZ DE HEREDIA
}

\author{
Santiago López-Ríos \\ Universidad Complutense de Madrid. Madrid, España \\ slrios@filol.ucm.es
}

\begin{abstract}
Resumen: Este artículo aborda un capítulo tan olvidado como significativo de la recepción de la Celestina en el siglo XX. Basándose en documentación de archivo, editada en el apéndice, analiza un proyecto de película que el cineasta franquista José Luis Sáenz de Heredia sugirió al director general de Cinematografía en otoño de 1955. El intercambio epistolar se produce pocos meses después de que Basilio Martín Patino publicara sobre el mismo asunto en Cinema universitario y de las famosas Conversaciones de Salamanca, en las que los jóvenes cineastas disidentes defendieron el neorrealismo como modelo para las películas españolas. De acuerdo con la ponencia del comunista Ricardo Muñoz Suay, la Celestina era un ejemplo claro de esa forma de entender el arte. A pesar de su interés en el clásico por influencia de Ramiro de Maeztu, Sáenz de Heredia, consciente de los infinitos problemas que una adaptación cinematográfica de la Tragicomedia de Calisto y Melibea podía tener con la censura franquista (él mismo confesó que "la Celestina era tabú en aquella época"), abandonó el proyecto.
\end{abstract}

Palabras clave: Celestina, Tragicomedia de Calisto y Melibea, José Luis Sáenz de Heredia, adaptaciones cinematográficas, censura franquista.

* Este artículo se inserta en las investigaciones del proyecto Epistolarios, memorias, diarios y otros géneros autobiográficos de la cultura española del medio siglo (referencia: FFI2013-41203-P), dirigido por el profesor José Teruel (Universidad Autónoma de Madrid) y financiado por el Ministerio de Economía y Competitividad. 


\begin{abstract}
This article focuses on an intriguing and overlooked chapter in the reception of La Celestina in the twentieth century. Based on archival documents transcribed in the appendix, it sheds light on a Celestina film project suggested to the General Director of Spanish Cinematography in fall 1955 by the Francoist film director, José Luis Sáenz de Heredia. The epistolary exchange took place a few months after Basilio Martín Patino wrote on this very subject in Cinema universitario, and after the famous Conversaciones de Salamanca, in which young dissident film producers argued in favour of neorealism as a model for Spanish cinema. According to the paper given at that conference by Communist Party member Ricardo Muñoz Suay, Celestina represented just such a form of artistic understanding. Despite an interest in the classic work inspired by Ramiro de Maeztu, Sáenz de Heredia was well aware of the many problems that a film adaptation of the Tragicomedia of Calisto and Melibea could face under strict Francoist censorship. The film director ultimately abandoned the project, later declaring that "Celestina was a taboo during that period".
\end{abstract}

Keywords: Celestina, Tragicomedia de Calisto y Melibea, José Luis Sáenz de Heredia, film adptation, Francoist censorship.

Recibido: 03.06.2014. Aceptado: 16.09.2014.

$\mathrm{S}$ E HA CONVERTIDO en casi un tópico referirse a lo malogradas que han resultado las cuatro adaptaciones cinematográficas de la Celestina con las que contamos a día de hoy: la italiana de Carlo Lizzani (1965), la hispano-alemana de César Fernández-Ardavín (1969), la mexicana de Miguel Sabido (1976) y la más reciente y conocida de Gerardo Vera (1996) (Antón Sánchez, 2000: 239-272; Hernández Ruiz, 2004; Utrera Macías, 2007: 2136; Moncho Aguirre, 2011: 102-104). "Hasta ahora no podemos decir que La Celestina haya tenido "fortuna cinematográfica" ha afirmado Manuel Ángel Vázquez Medel (2001: 126), a quien debemos uno de los estudios más destacados sobre el asunto.

Un aspecto de la fortuna de la Celestina en el cine aún por investigar es el obstáculo que la censura debió de suponer para que se abordaran largometrajes sobre la historia de Calisto y Melibea durante el franquismo. Según se muestra en este artículo, partiendo del análisis de unos documentos preservados en el Archivo General de la Administración (Alcalá de Henares, Madrid) y reproducidos en el apéndice, en verdad, sí se pensó en llevar la Celestina a la pantalla mucho antes de la versión de Lizzani. Nada menos que José Luis Sáenz de Heredia (1911-1992), uno de los directores más conspicuos del régimen, acarició el proyecto en 1955, fecha emblemática del cine español; el año de las Conversaciones de Salamanca y de Muerte de 
un ciclista de Juan Antonio Bardem. Sin embargo, todo quedó en wishful thinking: por más que Sáenz de Heredia, desde su completa sintonía con el franquismo, imaginara en explotar al máximo la españolidad del mito y soñara en adaptarlo hasta para el censor más intransigente, quizás $L a$ Celestina continuaba siendo demasiado peligrosa y el experimento, a la postre, se tornaba imposible.

En 1955 José Luis Sáenz de Heredia ocupaba un lugar preeminente en la cinematografía española ${ }^{1}$. Primo hermano de José Antonio Primo de Rivera y con cierta experiencia en el mundo del cine antes de 1936, gozaba de una reputación indiscutible y poseía una red de poderosos contactos, en especial, desde que resultó elegido para dirigir la adaptación de Raza (estrenada el 5 de enero de 1942), el libro que, con el seudónimo de Jaime de Andrade, había escrito el propio Francisco Franco. Desde esa superproducción y hasta mediados de los años 50, Sáenz de Heredia había acumulado un buen número de títulos y premios en su haber. Además, disponía de su propia productora, Chapalo Films, una empresa familiar, gestionada junto con su hermano Isidro, que recogía entonces pingües beneficios (Torreiro, 2011).

En este momento bastante dulce de la trayectoria de Sáenz de Heredia (ese verano había estrenado con extraordinario éxito Historias de la radio) hemos de situar una carta que el 22 de octubre de 1955 dirige a Manuel Torres López, responsable de la Dirección General de Cinematografía y Teatro, organismo dependiente del Ministerio de Información y Turismo, en manos entonces del ultraconservador Gabriel Arias Salgado. En esta misiva Sáenz de Heredia le expresa a Torres López su deseo de hacer una película sobre la Celestina. Dado que la preparación del guion implicaba un proceso laborioso, y temiendo que la censura lo rechazara, se había decidido a preguntar por "el criterio de esa Dirección General respecto a la versión cinematográfica" del libro. En su carta recurría también al argumento de haber tenido noticia "de un proyecto de coproducción franco-italiana sobre este mismo tema", lo que le preocupaba mucho, por el riesgo de que, desde el extranjero, se desvirtuara la esencia de este hito de la literatura española.

${ }^{1}$ Para estudios de conjunto sobre la obra de Sáenz de Heredia, véase Berthier (1998); Castro de Paz y Nieto Ferrando (eds.) (2011) y Monteverde (2011). 
El 8 de noviembre de 1955 Manuel Torres López daba respuesta a Sáenz de Heredia: en principio, no se planteaban inconvenientes para el proyecto, pero le aconsejaba que, antes de escribir el guion definitivo, preparase "una amplia y detallada sinopsis argumental", y que la sometiera al juicio de la censura. De ser el dictamen favorable, podría "afrontar la costosa y difícil tarea de escribir el guion definitivo" con mayores posibilidades de que, a su vez, éste fuera aprobado. El intercambio epistolar se interrumpe aquí, y no se conserva en el Archivo General de la Administración más documentación sobre un proyecto que Sáenz de Heredia jamás llevaría a término. Los interrogantes que suscitan estas cartas podrían quedar circunscritos a tres: el porqué del interés de Sáenz de Heredia en un largometraje de $L a$ Celestina, por qué airear el asunto justo en otoño de $1955 \mathrm{y}$, por último, las razones por las que desistió de ello. Al profundizar en estas cuestiones, contextualizando la documentación que se transcribe en el apéndice, se revelan algunos detalles que hacen que esta correspondencia trascienda lo meramente anecdótico.

Por un lado, a primera vista sorprende que José Luis Sáenz de Heredia, una persona de mentalidad tan conservadora y tan afín a la dictadura, se fijara en la Celestina. Si bien hemos de admitir que incluso hoy algunos críticos niegan el carácter heterodoxo de la obra y defienden la interpretación moralizante basándose en su deliberada ambigüedad, el libro, cuando menos, al siempre llamado "cineasta oficial del régimen" le resultaría problemático por el abierto tratamiento del sexo, la prostitución, el proxenetismo, por la despiadada sátira del clero corrupto, por las bromas soeces y la complacencia en el lenguaje obsceno. ¿Cómo podía sintonizar entonces la Celestina con el carácter y los gustos de este prohombre franquista, paradigma del nacional-católico y "caballero de esmerada educación que detestaba lo vulgar y zafio”? (Abajo de Pablos, 1996: 9).

Una primera explicación es que en los años 50 sigue en boga la tan rentable adaptación cinematográfica de obras literarias que se venía cultivando desde la década anterior (Pérez Bowie y González García, 2010). El propio Sáenz de Heredia había demostrado afición al género desde el inicio de su carrera. Además, por supuesto, se propondría una lectura edificante del original. El mismo director contaba con experiencia en ello, como ejemplifican su Don Juan y El escándalo (Utrera Macías, 2007: 109; Pérez Bowie, 
2004: 185). En realidad, la justicia poética se había vuelto un motivo recurrente en los filmes del director madrileño.

En una de las últimas entrevistas concedidas, Sáenz de Heredia rememoró cómo, al principio de su trayectoria, prefería buscar en la literatura la base de su cine: “[...] uno al principio apenas tiene fe en sí mismo [...]. Sin embargo, si uno hace, por ejemplo, Don Juan, Los tres mosqueteros o Hamlet, ya cree que con ese primer apoyo va a interesar al productor, que pondrá dinero", afirmó (Berthier, 2011: 266).

De todas formas, a pesar de cierta afición a la lectura, la lista de los libros predilectos de Sáenz de Heredia no nos revela, ni mucho menos, a un intelectual con profundas inquietudes, sino que, al contrario, sugiere conocimientos no demasiado amplios y gustos alejados de la Tragicomedia de Calisto y Melibea (Abajo de Pablos, 1996: 334-335).

¿De dónde entonces este súbito interés en la Celestina? ¿Simplemente por su pertenencia al canon? De ser así, podría haber escogido un texto como el Lazarillo de Tormes, más fácil de llevar a la pantalla desde una interpretación moralizante, como haría César Fernández-Ardavín en 1959 (Cruz Cámara y Kaplan, 2002; Pérez Bowie, 2004: 132-134). A la luz de los datos de que disponemos, cuesta creer que Sáenz de Heredia pensara en una versión cinematográfica de la Celestina a raíz de reflexiones personales sobre la profundidad y méritos literarios de la obra. Parece, en cambio, que no le atraía tanto que el libro formara parte del canon de la literatura española como la categoría de mito español por excelencia de la epónima alcahueta. En esto el director de cine reflejaba su deuda con un autor muy en particular: Ramiro de Maeztu.

El escritor vasco había publicado Don Quijote, don Juan y la Celestina, con un subtítulo elocuente, Ensayos en simpatía, a finales de 1925, en plena dictadura de Miguel Primo de Rivera, al que, frente a otros intelectuales, Maeztu manifestaría su apoyo. En este ensayo literario-filosófico late ya un evidente espíritu católico-conservador, indicio claro de un cambio ideológico que culmina en Defensa de la Hispanidad, compendio de postulados reaccionarios y de exaltación de la patria y lo español, que será venerado en el franquismo. Si para Maeztu don Quijote encarna el amor y don Juan el poder, Celestina simboliza el saber, pero discrepa de Menéndez Pelayo y asegura que la medianera no representa 'la ciencia del mal por 
el mal' (Maeztu 1925/2004: 151). Curiosamente también, pone el acento en la importancia de la condición de converso de Rojas para entender la obra, apuntando ideas que luego se encontrarán en Américo Castro y sus seguidores. A pesar del "carácter ético de estos ensayos de simpatización" (Maeztu 1925/2004: 34), esta visión tan nihilista de la Celestina y ciertas afirmaciones de Maeztu podrían entrar en conflicto con una estricta moral católica. Además, cualquier cineasta contemplaría con disgusto un comentario displicente que desliza en el prólogo: "Hay una forma de literatura a la que apenas se puede llamar arte: la novela de folletín, la película del cinematógrafo [...]" (Maeztu 1925/2004: 30). Sin embargo, nada hace pensar -y esto es lo importante- que Sáenz de Heredia hubiera profundizado en la Tragicomedia de Calisto y Melibea a través de una sosegada lectura del denso libro de Ramiro de Maeztu. La explicación se antoja mucho más simple y tal vez no haya que ir más allá de la portada del citado ensayo: para el cineasta la figura de la alcahueta integraba la terna de mitos españoles por antonomasia, "en simpatía" con don Quijote y don Juan, según postulaba el conocido título de un escritor de fama y prestigio indiscutibles en el franquismo por su condición de "mártir" en la Guerra Civil, lo que a Sáenz de Heredia, que había perdido a siete miembros de su familia en la contienda, le tocaba muy de cerca (Berthier, 2011: 269).

La admiración que debió de sentir el cineasta por Ramiro de Maeztu hemos de vincularla al hecho más dramático de su vida: como el autor de Defensa de la Hispanidad, él también fue hecho prisionero en Madrid al principio de la guerra y habría corrido la misma suerte que Maeztu, asesinado en 1936, de no haber intervenido Luis Buñuel, al que siempre reconoció deberle la vida (Abajo de Pablos, 1996: 25; Vizcaíno Casas y Jordán, 1988: 41-42).

Declaraciones del propio Sáenz de Heredia confirman que su asociación de las figuras de don Quijote, don Juan y Celestina en una trilogía de mitos hispánicos universales la hereda del escritor vasco: "considero, con Ramiro de Maeztu, que las tres aportaciones fundamentales de personajes en la literatura española son: don Quijote, la Celestina y don Juan" (Castro, 1974: 373). Este aserto coincide con su forma de ver el cine patrio, "una manifestación más del espíritu nacional” (Arocena, 2011: 116).

Por lo que afirma Sáenz de Heredia sobre su temor a que otros, con tai- 
mada intención y peor gusto, se adelanten en llevar la Celestina al cine, hay que señalar que, a principios de 1955, en España también se comentaba ya de forma abierta en ciertos círculos las posibilidades cinematográficas de este libro. Lo hacía un joven que, al margen de la filmografía del régimen, esa misma primavera iba a cobrar un protagonismo extraordinario y polémico en los debates en torno al cine español. En marzo, Basilio Martín Patino, en el primer número de Cinema universitario, la revista del cineclub del SEU de Salamanca, publicaba un original "Ensayo de adaptación cinematográfica de La Celestina” (Martín Patino, 1955). A sus veinticuatro años, Martín Patino, que había llegado al cine desde sus estudios de Filosofía y Letras en Salamanca escribe por primera vez -mérito digno de reconocerse- sobre los valores fílmicos de la Celestina, exhibiendo asombrosa lucidez y un notable conocimiento del texto. Sin olvidarse del desafío que exige la imprescindible adaptación lingüística, acierta al preferir, frente a la Tragicomedia, la versión de dieciséis actos, más trabada e intensa desde el punto de vista dramático. Razona, igualmente, sobre el asunto más delicado de todos, "el subido y escabroso realismo" de la obra, cubriendo sus comentarios de una poética y deliberada ambigüedad, con unas concesiones a la censura que invitan a leer entre líneas. El ensayo concluía con una propuesta de adaptación cinematográfica del principio y el fin de la Celestina.

Por más que Cinema universitario y sus responsables no fueran entusiastas del cine franquista, cuesta creer que el director de Raza hubiera pasado por alto el ensayo del estudiante. Era el primer número de una nueva revista de cine en la que, además, justo después del texto del futuro director de Nueve cartas a Berta, se publicaba el "llamamiento" para participar en las Primeras Conversaciones Cinematográficas de Salamanca, algo ante lo que Sáenz de Heredia no podía ni iba a permanecer indiferente (Boletín, 1955).

Este encuentro, celebrado en la Universidad de Salamanca entre el 14 y el 19 de mayo de 1955, constituye un episodio fundamental de la historia del cine español de posguerra (Francia, 1995; Nieto Ferrando y Company Ramón (eds.), 2006; Santamarina, 2011). En la idea y desarrollo de las Conversaciones influyó mucho el entorno de Objetivo, una revista disidente, fundada en 1953, con un Consejo de Redacción formado por Paulino 
Garagorri, un liberal orteguiano, y tres militantes del Partido Comunista de España: Ricardo Muñoz Suay, Eduardo Ducay y Juan Antonio Bardem. No obstante, el proyecto pudo fraguar porque el cine-club del SEU de Salamanca, a cuyo frente estaba Martín Patino, asumió la organización y dio su lugar a cineastas e intelectuales del régimen, José Luis Sáenz de Heredia incluido. En cualquier caso, la inquietud antifranquista entre los organizadores era manifiesta, y quedó plasmada en el célebre diagnóstico de Bardem (1955: 7-8) sobre el cine español del momento: "Políticamente ineficaz. Socialmente falso. Intelectualmente ínfimo. Estéticamente nulo. Industrialmente raquítico".

En varias ocasiones Sáenz de Heredia expresó con absoluta sinceridad la opinión que le merecieron las Conversaciones de Salamanca (Abajo de Pablos, 1996: 304-306; Berthier, 2011: 287-288). Siempre pensó que, con la excusa del cine, los organizadores aspiraban tan solo a hacer política antigubernamental (Berthier, 2011: 288). Tan a disgusto se sintió él como inquietos con su presencia los organizadores: "el fascismo militante mandó a José Luis Sáenz de Heredia, para ver qué puñetas estábamos haciendo allı", declaró Bardem (Castro, 1983: I, 122). "No olvido la larga despedida del veterano Sáenz de Heredia, 'todo un caballero', una hora de pie paseando ante el Gran Hotel, animándonos a seguir tan rebeldes, pero largándose aliviado en su Mercedes, por perdernos de vista”, escribió Martín Patino, más diplomáticamente (Martín Patino, 1995: 57).

Sabiendo del interés de Sáenz de Heredia en un largometraje de la Celestina y a la vista del ensayo de Martín Patino, la pregunta que nos asalta es si ambos cineastas tratarían del asunto en Salamanca, la ciudad en la que se piensa que transcurre la historia de Calisto y Melibea y en cuya universidad se supone que estudió Fernando de Rojas. Desde luego, el marco era más que propicio para evocar la obra, lo que no se le escapaba al cine-club del SEU, pues en el proyecto que elaboró en diciembre de 1954 contemplaba que el Teatro Popular Universitario (TPU) representara al aire libre la Celestina, con el fin de dar "prestancia y ambiente favorable a las sesiones de estudio", unas sesiones que respaldaron profesores de Filología y críticos literarios como Fernando Lázaro Carreter y Alonso Zamora Vicente (Proyecto, 2006: 283). Está claro que en el cine-club del SEU salmantino sabían de la adaptación teatral de la Celestina realizada por Felipe Lluch 
y que, bajo la dirección de Salvador Salazar, ensayaba el TPU de Madrid. Esta adaptación cosechó un gran éxito en el Festival Internacional de Teatro Universitario de Parma en abril de 1955. Además, se representó en Cáceres, al aire libre, durante otro festival universitario el 22 de junio, y fue emitida por Radio Nacional de España (Snow, 1985: 71).

No consta que Sáenz de Heredia dejara nada escrito sobre un intercambio de impresiones acerca de la Celestina con Basilio Martín Patino. Este último, casi cincuenta y nueve años después, tampoco lo recuerda, pero enfatiza el entusiasmo que, dados sus estudios de Filosofía y Letras y su estrecha relación con Salamanca, siempre le despertó la Tragicomedia de Calisto y Melibea ${ }^{2}$.

Aun en el supuesto de que Sáenz de Heredia y Martín Patino no departieran acerca de la adaptación cinematográfica de la Celestina durante las Conversaciones, sí sabemos que la obra salió a relucir en las jornadas; nada menos que en la ponencia de Ricardo Muñoz Suay. En su intervención, titulada "Caracteres de un cine español”, Muñoz Suay defendía sin rodeos el realismo como modelo a seguir en la representación de "los seres humanos, sus formas de vida, sus conflictos”, entendiéndolo como característica intrínseca del arte español. Negaba que el realismo se limitara a una mera "fórmula estética" y lo interpretaba más bien como un "estado de ánimo o una postura". Con un lenguaje filtrado de resonancias izquierdistas, para apoyar sus argumentos ofrecía una enumeración de ejemplos literarios, entre los que no faltaba la Tragicomedia de Calisto y Melibea: "Del Poema de Mío Cid a Los bravos de nuestro camarada Fernández Santos, el realismo adquiere variantes externas e internas diversas y bien determinadas. $L a$ Celestina, la novela picaresca, Don Quijote” (Muñoz Suay, 1955: 19, 20). Como ha escrito José Enrique Monterde (2006: 60), las Conversaciones de Salamanca simbolizaban "la definitiva entronización del Neorrealismo como modelo no mimético del empeño regeneracionista del cine español".

El texto de Muñoz Suay se imprimió en Objetivo al mes siguiente, junto con otras ponencias e información detallada acerca de las Conversaciones.

${ }^{2}$ Comunicación personal de Basilio Martín Patino a Santiago López-Ríos (8 de enero de 2014). 
Y en ese mismo número de Objetivo en el que Muñoz Suay citaba la $\mathrm{Ce}$ lestina, se reproducía también un artículo de Sáenz de Heredia aparecido poco antes en $A B C$ (Sáenz de Heredia, 1955). Hacia el verano de 1955, pues, la adaptación cinematográfica de La Celestina se había convertido en un asunto que interesaba en los círculos disidentes de la filmografía oficial y de ello parecía estar muy al tanto el director de Raza.

Volviendo a la carta de Sáenz de Heredia a Torres López, resulta imposible concretar si la referencia que hace a una supuesta coproducción italiano-francesa de la Celestina pudiera estar relacionada, de alguna manera, con las Conversaciones de Salamanca. De todas formas, no sería descabellado pensar que, por esas fechas, el marxista Carlo Lizzani (1922-2013) estuviera ya divulgando su idea de realizar un largometraje sobre la Celestina y los rumores al respecto se fueran extendiendo entre sus amigos cineastas españoles, quienes quizás hasta pudieron haber sido los que le inspiraron en la elección del tema. En 1965, Lizzani estrenaría en Italia su Celestina $P$. R., que "asume algunos aspectos propios de la comedia posneorrealista” (Hernández Ruiz, 2004: 135). Esta primera versión cinematográfica de la Tragicomedia ha sido calificada como un "auténtico precedente de un género que, poco después, se desplegaría en los aledaños del cine porno" (Utrera Macías, 2007: 27, n.3). En pocas palabras, la quintaesencia de lo que recelaba el director de Historias de la radio en su comunicación a Torres López, y paradigma del cine que más aborrecía:

En la mayor parte del cine que se hace ahora, al no existir un guion inteligente y con ingenio, se sacan de la manga rápidamente a las señoras desnudas, y ya está. Es posible que a otro señor le parezca que está bien ese desnudo, y entonces se hacen unas escenas que duran y duran interminablemente. Pero no es eso lo que hacíamos nosotros, no. Ni por censura, ni por gusto propio, ni por afán económico (Abajo de Pablos, 1996: 49).

$\mathrm{Al}$ margen de que en 1955 corrieran ya rumores sobre una adaptación de Lizzani, no hay duda de que, por esas fechas, el nombre del italiano no le era ajeno a Sáenz de Heredia y, vista la militancia política de aquel, tampoco le debía despertar ninguna simpatía. Aparte de tener noticia de 
su trayectoria al lado de Roberto Rossellini y Giuseppe De Santis, a Sáenz de Heredia no le pasaría inadvertido que en el número de Objetivo de mayo de 1955, en el que se hacía el llamamiento para las Conversaciones de Salamanca -y en el que, por cierto, Juan Antonio Bardem reseñaba muy negativamente La princesa de Éboli, coproducida por Chapalo Films- un artículo de Lizzani reivindicaba el valor de denuncia del cine neorrealista de su país y, de paso y de forma sutil, animaba a los jóvenes españoles a trabajar siguiendo esas directrices (Lizzani, 1955; Jordan, 1991; Monterde, 2006).

Habida cuenta de todo esto, resulta más que comprensible la preocupación con la que Sáenz de Heredia escribe a Torres López en otoño de 1955. $\mathrm{Al}$ director de Raza le sobraban razones para temer que la primera Celestina en el cine fuera una película neorrealista extranjera con intención de denuncia y explotando la obscenidad, lo que sería deplorable por partida doble: el alegato político y la manipulación zafia de un mito español.

Preocupaciones aparte, la carta de Sáenz de Heredia denota no solo que se sentía con autoridad en el mundo del cine español, sino también con bastante confianza en el destinatario de su escrito. Manuel Torres López era un destacado falangista, catedrático de Derecho que, después de haber desempeñado el cargo de vocal en la Junta de Clasificación y Censura de Películas Cinematográficas, había sido nombrado director general de Cinematografía el 25 febrero de 1955. Por lo que respecta a su relación con Sáenz de Heredia, Carlos Heredero desvela un detalle relevante: en 1955 el organismo que dirigía Torres López dispensó "cierto trato de favor" a Sáenz de Heredia y a la productora Chapalo Films, que se tradujo en un extraordinario negocio para Historias de la radio, la comedia que se estrenaría el 25 de julio. Aparte de que se aceptara un presupuesto muy abultado del filme, también se le concedió la calificación de "Interés Nacional" y el segundo premio del Sindicato Nacional del Espectáculo. Estos galardones implicaron, a su vez, mucho dinero para una película que también facturó cuantiosas cantidades en taquilla (Heredero, 2011: 168-169). En estas circunstancias, resulta más fácil de entender la libertad que, al escribir a Torres López directamente, se permite Sáenz de Heredia, quien reconoce que ha recurrido a una vía bastante irregular para indagar acerca de una cuestión vidriosa. 
De todas formas, Sáenz de Heredia sabía a la perfección lo que conllevaba la censura. Desde luego, en octubre aún no habría olvidado los quebraderos de cabeza que, hasta los primeros meses de 1955, le venía causando La princesa de Éboli/That Lady, una coproducción de Chapalo Films con la británica Atalanta Films. La censura rechazó el primer guion de esta película que dirigiría Terence Young con Olivia de Havilland en el papel estelar. Introducidos los oportunos cambios en el guion, se le concedió el visto bueno y la película acabó rodándose. Sin embargo, pronto surgió un nuevo conflicto al extenderse la noticia de que existía una segunda versión, en inglés, para burlar el control y distribuirse en el extranjero. El escándalo alcanzó tales dimensiones que el director general de Cinematografía, Joaquín Argamasilla de la Cerda, marqués de Santa Clara, fue destituido y en su lugar se nombró a Torres López (Castro, 1974: 375; Gubern, 1981: 138140; Abajo de Pablos, 1996: 98-100; Cancio Fernández, 2009: 163-164; Berthier, 2011: 273).

Estando al corriente de cómo funcionaba el organismo censor y después de la experiencia con La princesa de Éboli, Sáenz de Heredia, antes de escribir a Torres López, según se ve en esta carta transcrita en el apéndice, eligió muy bien cómo sondear el terreno al entrar en contacto con Francisco Ortiz Muñoz, presumiblemente en el verano de 1955, mientras saboreaba el éxito de Historias de la radio. Después de una larga experiencia, este censor había publicado unas reflexiones en torno a su oficio, en las que abominaba, una y otra vez, de las escenas de sexo en la pantalla (Ortiz Muñoz, 1946). Por otro lado, estas gestiones de Sáenz de Heredia encajan dentro de un clima de rumores en torno a un supuesto nuevo código de censura que Torres López iba a promulgar (Gubern, 1981: 152). Sin embargo, el catedrático de Derecho acabaría viéndose obligado a abandonar el puesto por su gestión del espinoso asunto de las Conversaciones de Salamanca. En cuanto a la revista disidente, el último número de Objetivo que pudo salir a la calle fue el de septiembre-octubre de 1955. Varios miembros del entorno de la revista fueron detenidos, coincidiendo con un ambiente de gran tensión que desembocó en las protestas estudiantiles de febrero de 1956. En abril de ese año, se nombraba director general de Cinematografía a Juan Muñoz Fontán, vizconde de San Javier (Gubern, 1981: 152; Cancio Fernández, 2009: 166; Lizcano (1981/2006). 
Sin duda, el cambio de director general hubo de contribuir a que Sáenz de Heredia desistiera de su idea de llevar la Celestina al cine. Además, debió de reflexionar con mayor detenimiento sobre las infinitas objeciones que la censura pondría a un guion sobre la historia de Calisto y Melibea. No olvidemos que Gabriel Arias Salgado continuaba al frente del Ministerio de Información y Turismo y, durante esta época, "autores claramente adscritos al régimen, e incluso sostenidos y promocionados por hombres prominentes del mismo, cayeron víctimas de la censura" (Abellán, 1980: 94). Por lo que respecta al cine, con Juan Muñoz Fontán "la función censora se siguió practicando con severidad" (Gubern, 1981: 153).

Parece entonces lógico que Sáenz de Heredia, firme partidario del control moral y político del cine por parte del Gobierno, decidiera invertir sus esfuerzos en otros filmes y abandonase un proyecto que, por otra parte, podía ser ruinoso. Aunque nunca facilitó detalles al respecto, sí hizo un comentario que, en su laconismo, lo dice todo. Al hablar de los tres mitos literarios hispánicos, explica que solo llegó a rodar Don Juan, por la inmensa complejidad del Quijote y porque "la Celestina era tabú en aquella época" (Castro, 1974: 373). Al final, Sáenz de Heredia prefirió la autocensura a la censura, con la que siempre había comulgado. En la última entrevista que concedió en su vida haría gala de esta coherencia. Negando que el organismo censor hubiera puesto alguna vez objeciones a sus películas, concluía tajante: "Creo que la censura a mí nunca me quitó nada" (Berthier, 2011: $273)^{3}$.

${ }^{3}$ Agradezco la ayuda que en esta investigación me han prestado el Sr. Basilio Martín Patino, el Dr. D. Kuehl, el Dr. S. Sanz Villanueva y el Dr. J. Teruel. Estoy también en deuda con la profesora Luce López-Baralt y los colegas del Departamento de Estudios Hispánicos de la Universidad de Puerto Rico-Río Piedras, por su invitación a exponerles una visión preliminar de este trabajo en primavera de 2014. 


\section{APÉNDICE}

Archivo General de la Administración (Alcalá de Henares, Madrid), Sección Cultura, Ministerio de Información y Turismo, Fondo Dirección General de Cinematografía y Teatro, caja 36/o4574. Expediente reproducido con autorización. Se moderniza acentuación y puntuación, según normas actuales.

\section{[Documento 1]}

José Luis Sáenz de Heredia

Madrid, 22 de octubre de 1955

Ilmo. Sr. D. Manuel Torres López

Director General de Cinematografía y Teatro

MADRID

Mi distinguido amigo:

Hace ya unos cuatro meses hablé con Ortiz Muñoz y le expuse mi deseo de realizar en cine La Celestina. Me dijo que lo había consultado con Vd. y me transmitió que era preferible aplazar la determinación para más adelante. Hoy vuelvo sobre ello y me dirijo directa y antirreglamentariamente a Vd. por dos razones. La primera es que, en realidad, yo no puedo presentar un guion, sino la aspiración a hacerlo. Es este un trabajo difícil y denso que, por fuerza, llevará mucho tiempo y es lógico que, antes de emplearme en ello, quiera saber el criterio de esa Dirección General respecto a la versión cinematográfica, ya que sería lastimoso para mí haber perdido tres o cuatro meses, caso de que al presentar el guion al Departamento de Censura, no se autorizase la realización.

La segunda razón que me obliga a utilizar esta vía, repito, inadecuada, es la de tener noticias de un proyecto de coproducción francoitaliana sobre este mismo tema. No es la primera vez que se baraja este título entre los productores de otros países y tarde o temprano, si no nos adelantamos nosotros (con más obligación y derecho), la harán, y sin el respeto y consideración que nosotros le debemos a esta joya de nuestro patrimonio literario, sino tomando de ella la parte maliciosa a que el personaje se presta, para hacer simplemente una película semipornográfica, apoyada en un "tema clásico español”.

Por estos dos motivos le molesto y le ruego una contestación.

Muy afectuosamente le saluda,

José Luis Sáenz de Heredia. 
[Documento 2] [Minuta]

Madrid, 25 de octubre de 1955

Sr. D. José Luis Sáez [sic] de Heredia

Madrid

Mi distinguido amigo:

He recibido su carta del día 22 en la que hace referencia al proyecto de adaptar cinematográficamente La Celestina.

Esta Dirección General, habida cuenta las características que concurren en la obra literaria cuya adaptación se pretende, así como sus deseos de ser informado sobre el criterio que su realización cinematográfica pueda merecer a este organismo, procede a estudiar su petición, previa las oportunas consultas a la Superioridad. Así que se haya resuelto en definitiva, volveré a escribirle indicándole la resolución adoptada que, por mi parte, vería con agrado fuese favorable, habida cuenta que se trata de una de las obras clásicas más destacadas de la literatura española.

Confiando poder comunicarle en fecha próxima nuevas y más concretas noticias, le saluda atentamente y queda suyo affmo.,

Manuel Torres López.

[Documento 3]

CHAPALO FILMS

ISIDRO SÁENZ DE HEREDIA

Producción, importación y exportación de películas

General Mola, 293 (Chamartín)- Dirección Telegráfica: “Chapalofilms"

Teléfono 338570

Madrid

27 de octubre de 1955

Excmo. Sr. D. Manuel Torres López

Director General de Cinematografía y Teatro

Fernando el Santo, 20

Madrid

Mi distinguido amigo:

Recibo su atenta carta, 25 del corriente, la que contesto por estar mi hermano ausente de Madrid, para agradecerle en su nombre y en el mío 
propio la rapidez e interés que demuestra por el asunto que le planteamos en la nuestra anterior.

Esperando interesados la resolución que tenga a bien determinar, le saluda atentamente y queda suyo affmo.,

Fdo. Isidro Sáenz de Heredia.

\section{[Documento 4] [minuta]}

Sr. D. José Luis Sáenz de Heredia

CHAPALO FILMS

Madrid

Mi distinguido amigo:

Como continuación a mi carta de 25 de octubre último relativa al proyecto que tiene esa productora de llevar al cine La Celestina, tengo el gusto de manifestarle que por parte de esta Dirección General no existe en principio ningún inconveniente en que dicho proyecto se haga realidad, si bien no se puede dar un dictamen definitivo sobre la adaptación cinematográfica de la citada obra literaria hasta tanto que por esa Casa se presente en este organismo el guion correspondiente.

He de destacar ante Vd. que, naturalmente, la adaptación cinematográfica de La Celestina debe reflejar y respetar las fundamentales características y el desarrollo argumental de la obra original, si bien tratados con la habilidad necesaria para que no resulten rechazables en su expresión cinematográfica aspectos o situaciones perfectamente aceptables en una obra clásica eminentemente literaria y de difusión restringida.

Por mi parte, estimo que, para eludir el intenso trabajo que supondría la construcción del guion definitivo, con el consiguiente riesgo de que en algunos aspectos pudiera ofrecer posteriores reparos, sería preferible que por Vd. se presentase en este organismo una amplia y detallada sinopsis argumental que permitiera valorar la adaptación cinematográfica prevista y ponderar el tono en que serán desarrollados determinados pasajes de dicha obra.

En consecuencia, si Vd. estima aceptables las sugestiones que le hago, puede presentar la sinopsis en cuestión, para que, una vez informada aquella pueda ya, si según espero es favorablemente, afrontar la costosa y difícil tarea de escribir el guion definitivo.

Esperando sus noticias, le saluda afectuosamente y queda suyo buen amigo,

Manuel Torres López. 


\section{Referencias}

Abajo de Pablos, J. J. de. (1996). Mis charlas con José Luis Sáenz de Heredia. Valladolid: Quirón Ediciones.

Abellán, M. L. (1980). Censura y creación literaria en España (1939-1976). Barcelona: Península.

Alsina Calvés, J. (2011). Don Quijote, Don Juan y la Celestina de Ramiro de Maeztu. El Catoplepas. Revista Crítica del Presente, 113, 11. Disponible en http://www.nodulo.org/ec/2011/n113p11.htm

Antón Sánchez, L. (2000). César Fernández-Ardavín: Cine y autoría. Madrid: Egeda.

Arocena, C. (2011). Fulgores en tiempos de cambio. El cine de José Luis Sáenz de Heredia en la década de los cincuenta. En Castro de Paz, J. L. y Nieto Ferrando, J. (eds.), El destino se disculpa. El cine de José Luis Sáenz de Heredia (pp. 115-130). Valencia: Ediciones de la Filmoteca.

Bardem, J. A. (1955). Informe sobre la situación actual de nuestra cinematografía. Objetivo. Revista del Cinema, 6, 7-8.

Berthier, N. (1998). Le franquisme et son image. Cinéma et propagande. Toulouse: Presses Universitaires du Mirail.

(2011). Entrevista a José Luis Sáenz de Heredia (septiembre-octubre de 1991). En Castro de Paz, J. L. y Nieto Ferrando, J. (eds.), El destino se disculpa. El cine de José Luis Sáenz de Heredia (pp. 265-289). Valencia: Ediciones de la Filmoteca.

Boletín de las Primeras Conversaciones Cinematográficas Nacionales. Llamamiento. (1955). Cinema universitario, 1, 65-86.

Cancio Fernández, R. C. (2009). La acción administrativa sobre el hecho cinematográfico durante el franquismo. Revista de Derecho UNED, 5, 149-183.

Castro, A. (1974). El cine español en el banquillo. Valencia: Fernando Torres Editor.

(1983). Estudio de la obra cinematográfica de Juan Antonio Bardem. Tesis doctoral. Madrid: Universidad Complutense de Madrid.

Castro de Paz, J. L. y Nieto Ferrando, J. (eds.). (2011). El destino se disculpa. El cine de José Luis Sáenz de Heredia. Valencia: Ediciones de la Filmoteca.

Cruz Cámara, N. y Kaplan, G. (2002). Una revisitación franquista del Lazarillo de Tormes. En Mínguez Arranz, N. (ed.), Literatura española y cine (pp. 27-42). Madrid: Editorial Complutense.

Francia, I. (1995). Antes de Salamanca, en Salamanca, después de Salamanca. Crónica de las Conversaciones. En Escudero, J. M.; Bardem, J. A.; Lara, F.; Heredero, C. F.; Querejeta, E.; Patino, B. M. y Francia, I. (eds.), El cine español, desde Salamanca (1955/1995) (pp. 59-76). Salamanca: Filmoteca de Castilla y León. 
Gubern, R. (1981). La censura. Función política y ordenamiento jurídico bajo el franquismo (1936-1975). Barcelona: Península.

Heredero, C. F. (2011). Historias de la radio. Radiografía de la penuria vitalista. En Castro de Paz, J. L. y Nieto Ferrando, J. (eds.), El destino se disculpa. El cine de José Luis Sáenz de Heredia (pp. 161-169). Valencia: Ediciones de la Filmoteca.

Hernández Ruiz, J. (2004). La Celestina, don Juan el Quijote en las pantallas. Luces y sombras de sus recreaciones audiovisuales. En Díez, J. L. (ed.), Tres mitos españoles. La Celestina. Don Quïote. Don Juan (pp. 133-169). Madrid: SECC.

Jordan, B. (1991). Culture and Opposition in Franco's Spain: The reception of Italian Neo-Realist cinema in the 1950s. European History Quarterly, 21, 209-238.

Lizcano, P. (1981/2006). La generación del 56. La Universidad contra Franco. Madrid: Saber y Comunicación.

Lizzani, C. (1955). El artista frente a la realidad. Objetivo. Revista del cinema, 5, 9-14.

Maeztu, R. de. (1925/2004). Don Quijote, don Juan y la Celestina. Ed. JoséCarlos Mainer. Madrid: Comunidad de Madrid-Visor.

Martín Patino, B. (1955). Ensayo de adaptación cinematográfica de La Celestina. Cinema universitario, $1,75^{-84}$.

(1995). Carta a Juan Antonio Pérez Millán sobre aquello de Salamanca y otras reflexiones subyacentes. En Escudero, J. M.; Bardem, J. A.; Lara, F.; Heredero, C. F.; Querejeta, E.; Patino, B. M. y Francia, I. (eds.), El cine español, desde Salamanca (1955/1995) (pp. 55-58). Salamanca: Filmoteca de Castilla y León.

Moncho Aguirre, J. de M. (2011). Teatro capturado por la cámara. Obras teatrales españolas en el cine (1898-2009). Alicante: Instituto Alicantino de Cultura Juan Gil-Albert.

Monterde, J. E. (2006). Del neorrealismo y el cine español. En Nieto Ferrando, J. y Company Ramón, J. M. (eds.), Por un cine de lo real. Cincuenta años después de las conversaciones de Salamanca (pp. 282-283). Valencia: Ediciones de la Filmoteca.

(2011). José Luis Sáenz de Heredia Osío. En Carlos F. Heredero y Eduardo Rodríguez Merchán (eds.), Diccionario del cine iberoamericano. España, Portugal y América (VII, pp. 641-647). Madrid: SGAE-Fundación Autor.

Muñoz Suay, R. (1955). Caracteres de un cine español. Objetivo. Revista del cinema, 6, 19-21.

Nieto Ferrando, J. y Company Ramón, J. M. (eds.) (2006). Por un cine de lo real. Cincuenta años después de las conversaciones de Salamanca. Valencia: Ediciones de la Filmoteca. 
Ortiz Muñoz, F. (1946). Criterios y normas morales de censura cinematográfica. Madrid: Editorial Magisterio Español.

Pérez Bowie, J. A. (2004). Cine, literatura y poder. La adaptación cinematográfica durante el primer franquismo (1939-1950). Salamanca: Librería Cervantes.

Pérez Bowie, J. A. y González García, F. (2010). El mercado vigilado. La adaptación al cine español de los 50. Murcia: Tres Fronteras Ediciones.

Proyecto para unas jornadas internacionales de estudio sobre la universidad y el cine organizadas por el Cine-Club del SEU de Salamanca. En Nieto Ferrando, J. y Company Ramón, J. M. (eds.), Por un cine de lo real. Cincuenta años después de las conversaciones de Salamanca (pp. 282-283). Valencia: Ediciones de la Filmoteca.

Sáenz de Heredia, J. L. (1955). ¿Quién tiene el clavel? Objetivo. Revista del cinema, 6,4 .

Santamarina, A. (2011). Conversaciones de Salamanca. En Heredero, C. F.; Rodríguez Merchán, C. y E. (eds.), Diccionario del cine iberoamericano. España, Portugal y América (II, pp. 817-820). Madrid: SGAE-Fundación Autor.

Snow, J. T. (1985). Celestina by Fernando de Rojas. An Annotated Bibliography of World Interest: 1930-1985. Madison: Hispanic Seminary of Medieval Studies.

Torreiro, C. (2011). Chapalo Films, una empresa familiar. En Castro de Paz, J. L. y Nieto Ferrando, J. (eds.), El destino se disculpa. El cine de José Luis Sáenz de Heredia (pp. 131-138). Valencia: Ediciones de la Filmoteca.

Tuñón, J. (2011). Sin 'cieno ni obscenidad': El censor de películas Francisco Ortiz Muñoz, inventor de su propio paraíso (1946). Historias, 79, 19-48.

Utrera Macías, R. (2007). Literatura y cine. Adaptaciones. I. Del teatro al cine. Sevilla: Eihceroa.

Vázquez Medel, M. Á. (2001). La Celestina, de la literatura al cine. En Torres, G. (ed.), Celestina: recepción y herencia de un mito literario (pp. 125-141). Cáceres: Universidad de Extremadura.

Vizcaíno Casas, F. y Jordán, Á. A. (1988). De la checa a la meca. Una vida de cine. Madrid: Planeta. 